\title{
Synergies between App-Based Car-Related Shared Mobility Services for the Development of More Profitable Business Models
}

\author{
Mireia Gilibert ${ }^{1,2}$ (D) Imma Ribas $^{1}$ \\ ${ }^{1}$ Universitat Politècnica de Catalunya (Spain) \\ ${ }^{2}$ SEAT, S.A. (Spain) \\ mireia.gilibert@upc.edu,imma.ribas@upc.edu
}

Received: May 2019

Accepted: September 2019

\begin{abstract}
:
Purpose: Emerging shared mobility services are an opportunity for cities to reduce the number of car single trips to both improve traffic congestion and the environment. Users of shared mobility services, such as carsharing, ridesharing and singular and shared ride-hailing services, often need to be customers of more than one service to cover all their transport needs, since few mobility providers offer more than one of these services from a single platform. On the other hand, providers offering these services separately do not optimise costly resources and activities, such as the vehicles or the technology. Hence, the aim of this paper is to find synergies between the different app-based car-related shared mobility services that foster the development of new business models, to increase the profitability of these services.
\end{abstract}

Design/methodology/approach: The research approach is built on the literature of car-related shared mobility services business models, supported by the review of certain outstanding services websites, and face-to-face interviews with users and drivers of these transport services. The analysis is presented by means of the Business Model Canvas methodology.

Findings: Based on the synergies found, this paper suggests a few different approaches for services to share some resources and activities.

Originality/value: This study identifies the common features of carsharing, ridesharing and singular and shared ride-hailing services to develop more profitable business models, based on providing the services in aggregated form, or outsourcing activities and resources. In addition, the implications of these proposals are discussed as advantages and drawbacks from a business perspective.

Keywords: shared transport services, car sharing, ride hailing, ride sharing, business model

\section{To cite this article:}

Gilibert, M., \& Ribas, I. (2019). Synergies between app-based car-related shared mobility services for the development of more profitable business models. Journal of Industrial Engineering and Management, 12(3), 405-420. https://doi.org/10.3926/jiem.2930 


\section{Introduction}

The mobility sector has seen a growth in app-based on-demand shared transport initiatives, such as renting a car by the hour or minute (carsharing) and taking a ride in a shared vehicle (ride-sourcing). These new mobility business models have changed the urban mobility sector from a limited transportation offer to a scenario full of new players offering mobility-on-demand in different ways. Some cities are reacting to this uncontrolled expansion, such as London, trying to ban the ride-bailing services of Uber, or New York, announcing restrictions on the number of vehicles providing ride-hailing services (Goldman, 2017). However, Martínez, Viegas, Crist and Martinie (2015) and Alonso-Mora, Samaranayake, Wallar, Frazzoli and Rus (2017) estimated that if the rides would be shared, the number of vehicles in the cities would greatly decrease. Besides, on one hand, ride-sourcing provides a transport solution at a low investment to peripheral neighbourhoods with inefficient access to public transport. For instance, Morozov (2016) explained that some U.S. local administrations asked Uber -in exchange for significant subsidies- to assume public transport functions in areas where infrastructure was poor; and Watanabe, Naveed, Neittaanmäki, and Fox (2017) remarked that in countries like Saudi Arabia Uber offers reliable transportation to women, thus enabling them to have jobs. On the other hand, carsharing offers cities the possibility of reducing their total number of vehicles, which spend more than $90 \%$ of their lives parked on the streets, and it exchanges the vehicles in use for more sustainable ones (Zhang, Spieser, Frazzoli \& Pavone, 2015).

A number of papers have suggested a classification of app-based car-related shared mobility services. Regarding carsharing services, Shaheen, Mallery and Kingsley (2012) identified four models of Peer-to-Peer (P2P) carsharing according to the business model portion of the carsharing platform; Cohen and Kietzmann (2014) and Münzel, Boon, Frenken and Vaskelainen (2017) distinguished between the business type (Business-to-Consumer (B2C), P2P, non-profit and cooperative carsharing) and the operational model (one-way and round-trip); Remane, Nickerson, Hanelt, Tesch and Kolbe (2016) divided carsharing business models into 7 clusters according to the business type: the operational model, the vehicle offer and the type of access (manual or automatic); and Rotaris and Danielis (2017) classified the service according to who owns and maintains the car. Furthermore, Bälan (2016) classified the main models of carsharing, ridesharing and ride-bailing that exist in Romania, regardless of whether or not they are profitable; and Chan and Shaheen (2012) distinguished between different types of ride-sharing based on the relationships among their participants.

It can be observed that these papers used different business characteristics to classify the mobility services being considered. Hence, to give a general overview of all types of for-profit services, we present a more comprehensive classification that summarises the several classifications provided by the above-mentioned studies (Figure 1). First, we divide the shared mobility business models into two main areas: ride-sourcing, which refers to the services of ride-bailing and ridesharing; and vehicle sharing, which is based on renting vehicles for short periods of time.

Ride-hailing is interpreted here as the business model that operates like taxis, with the difference being that this service is not authorised to pick up street hails, and therefore, requires passengers to previously book their trips. As defined in Figure 1, ride-bailing is divided into private B2C (chauffeur driven vehicles commonly called VTC services, i.e., Chauffeured Tourism Vehicle), private P2P, where people seek economic remuneration by working as drivers and using their cars to carry passengers to their destinations, and shared B2C and P2P models. On the other hand, ridesharing is defined as a non-profit activity, where both drivers and passengers share similar destinations and decide to share trips in order to share travel costs (Chan \& Shaheen, 2012). However, some for-profit services exist, such as BlaBlaCar and Amovens, who apply an organisation-based model using internet platforms. Therefore, in this paper only the ridesharing organisation-based model that operates through for-profit internet platforms is analysed. To summarise, the main difference between shared ride-hailing and ridesharing is: in the former, drivers are employed or work freelance, whereas in the last, drivers seek only to share the costs of their regular or occasional long trips. It is worth noting that this difference will disappear once these services are offered with autonomous vehicles.

Finally, carsharing business models are classified into four business types: B2C, P2P, corporate carsharing and target-oriented (e.g., cooperatives, municipally owned and private communities). In the case of corporate carsharing and P2P, they usually operate using the round-trip mode, where users are requested to return the vehicles to the pick-up locations. However, some P2P carsharing services also offer the option of requesting and offering a home pick-up and delivery service. B2C carsharing services can be found that use either round-trip or one-way modes. The one-way (or 
point-to-point) type allows users to return the vehicles near their destinations at specific points (station-based) or directly on the streets (free-floating or flexible). Therefore, the point-to-point model is suitable for short urban trips; whereas the round-trip type covers longer distance trips.

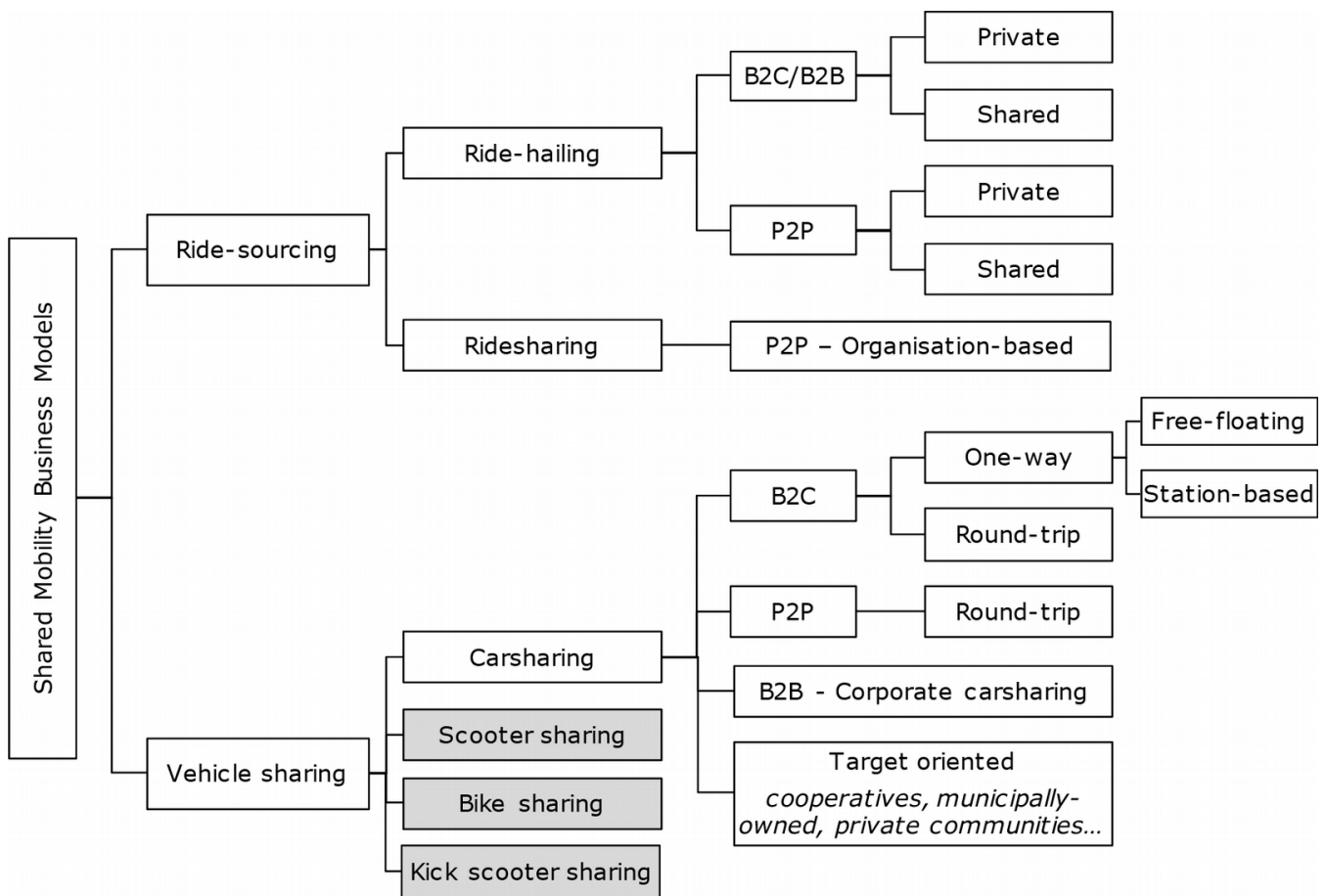

Figure 1. Classification of for-profit shared mobility business models from the business point of view

The scope of this research is limited to car-related services, thus the business models of scooter sharing, bike sharing and kick scooter sharing are not analysed.

These emerging shared mobility services concern and challenge the traditional passenger transport services, and in particular, the automotive industry, who might see their sales fall. Therefore, automakers are investing, acquiring and partnering these services, or even creating their own, as well as their own mobility ecosystems. For instance, Daimler launched the carsharing services of car2go and Croove, in addition to the mobility platform moovel; acquired the taxi-hailing services mytaxi and Hailo, set up a joint venture with the shared ride-hailing Via, and invested in the singular ride-bailing Blacklane. Lastly, at the beginning of 2019, Daimler started a cooperation with its competitor BMW, to consolidate the above-mentioned services by unifying them with those of BMW. Besides, other big automakers such as Volkswagen, Toyota, Ford or General Motors are also building their mobility ecosystem in a similar way.

Nowadays, most services providers offer the different mobility services separately (i.e. not sharing the application, vehicles and staff with other services offered by the same company). Besides, many of these transport services are unprofitable, and for this reason end up closing down, moving to other cities or changing their business model. Therefore, this paper aims at answering the following research question: What are the synergies between for-profit car-related shared mobility services - carsharing, ridesharing and ride-hailing- that foster the development of more profitable business models?

The research question is addressed in this paper by examining relevant similarities and differences among these types of services, using the Business Model Canvas (BMC) methodology (Osterwalder, Pigneur \& Tucci, 2005) to identify them, and relying on different sources of information: literature review, services websites, face-to-face interviews with users and drivers, and personal experience.

The rest of the paper is organised as follows: the second section explains the methodology used to conduct the research process. The third section presents the main characteristics of the app-based car-related shared mobility 
services business models, based mainly on the literature review and services websites, through the nine building blocks of the BMC. Next, a discussion about the conducted research is given, and finally, the conclusions and future lines of research are presented.

\section{Methodology}

We investigated the common features and differences of the different types of app-based car mobility services by analysing their business models by means of the BMC methodology. The BMC provides a detailed and clear visual overview of how business operates, and it is a helpful tool for identifying what activities are the most important for creating and delivering value to stakeholders while generating innovative revenue streams.

First, we conducted a literature review based on specific research using as keywords the combination of the terms "business model" with "shared mobility", "mobility services" or the names of the existing car-related shared mobility services: "carsharing", "ridesharing" and "ride-hailing". We conducted the search in the electronic databases SCOPUS and Web of Science from the $1^{\text {st }}$ January 2000 until the $31^{\text {st }}$ December 2018.

Second, to include the commercial and operational perspective in our research, we inspected the websites of 19 outstanding services of singular and shared ride-hailing, B2C and P2P carsharing, and ridesharing, being few of them offered by the same provider and through the same application.

Finally, to appreciate the differences between these transport services and better define their value proposition and the targeted customer segments from users' point of view, as well as the strengths and weaknesses of the services, we reviewed the last users' comments posted on their App Store and Google Play pages (Apple Inc., 2018; Google, 2018), we experienced some of the services, and conducted 30 semi-structured face-to-face interviews with users and 7 with drivers of ride-hailing and ridesharing services. Both the surveys and the tests were conducted in different cities of Spain, Germany and the United States.

With regard to the interviews, we mainly asked users the following questions: when and why they used the specific services, what they liked and disliked, and why they did not choose other transport services for these trips. As for the drivers, we asked them why they drove for the service, and also, what they liked and disliked.

Table 1 specifies the services that have been reviewed through their websites, and App Store and Google Play pages, by type of service; and the number of conducted interviews and tests for each type. Data was collected from July 2017 until December 2018, and was classified, just as the literature review, according to the 9 building blocks of the BMC.

\begin{tabular}{|c|c|c|}
\hline Type of service & Operating services reviewed & $\begin{array}{l}\text { No of interviews } \\
\text { and tests }\end{array}$ \\
\hline \multirow{2}{*}{ Ride-bailing } & $\begin{array}{c}\text { Singular } \\
\text { Didi Chuxing (2018), mytaxi (2017), Gett (2017), Uber (2017), Lyft (2018), } \\
\text { Maxi Mobility (2017), ReachNow (2018) }\end{array}$ & $\begin{array}{l}10 \text { users } \\
3 \text { driver } \\
5 \text { tests }\end{array}$ \\
\hline & $\begin{array}{l}\text { Shared } \\
\text { Via (2018), CleverShuttle (2018), Uber (2017), Lyft (2018) }\end{array}$ & $\begin{array}{l}7 \text { users } \\
2 \text { driver } \\
3 \text { tests }\end{array}$ \\
\hline Ridesharing & Blablacar (2018), Waze (2018), Amovens Soluciones (2017) & $\begin{array}{l}3 \text { users } \\
2 \text { drivers } \\
2 \text { tests }\end{array}$ \\
\hline \multirow[t]{2}{*}{ Carsharing } & $\begin{array}{c}\text { B2C } \\
\text { Zipcar (2017), car2go (2017), DriveNow (2017), ReachNow (2018), Respiro } \\
\text { (2018), Wible (2018) }\end{array}$ & $\begin{array}{l}8 \text { users } \\
2 \text { tests }\end{array}$ \\
\hline & $\begin{array}{c}\text { P2P } \\
\text { Drivy (2017), SocialCar (2017), Amovens Soluciones (2017) }\end{array}$ & 2 users \\
\hline
\end{tabular}

Table 1. List of services reviewed through their websites and number of interviews and tests conducted, by type of service. 


\section{Business Model Canvas Perspective on Shared Mobility Services}

In this section, all the information obtained from the literature review, the websites of existing mobility services, their App Store and Google Play pages, the tests, and the interviews, is analysed using the nine building blocks of the Business Model Canvas: Customer Segments, Value Propositions, Channels, Customer Relationships, Revenue Streams, Key Resources, Key Activities, Key Partnerships, and Cost Structure.

Figure 2 summarises and distinguishes the key features of each building block, per type of service analysed: ride-bailing, ridesharing and carsharing. Next sections are devoted to analyse each of these blocks.

\begin{tabular}{|c|c|c|c|c|c|c|}
\hline 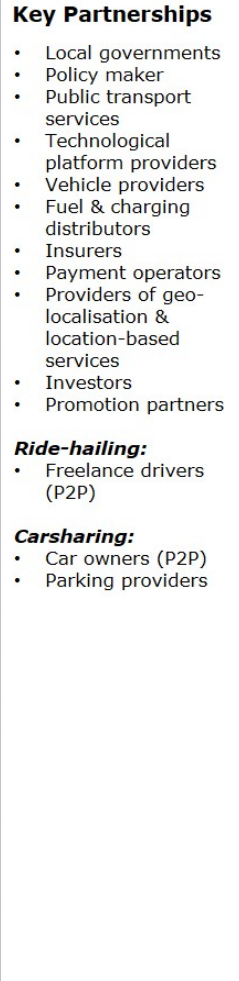 & \multicolumn{3}{|c|}{ 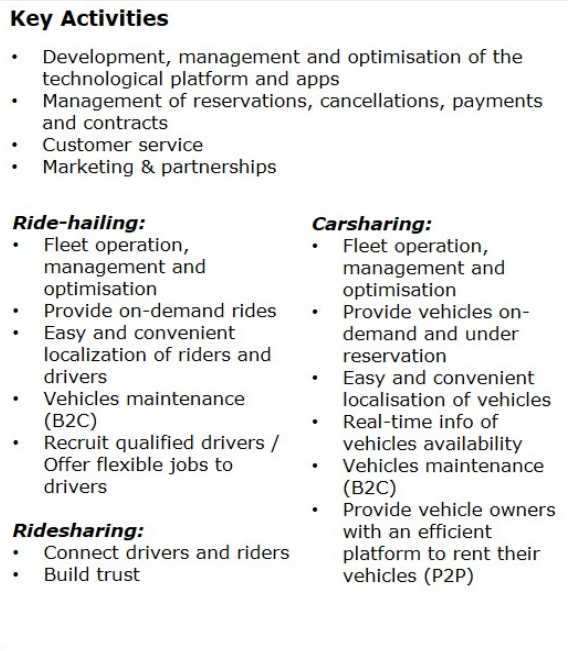 } & 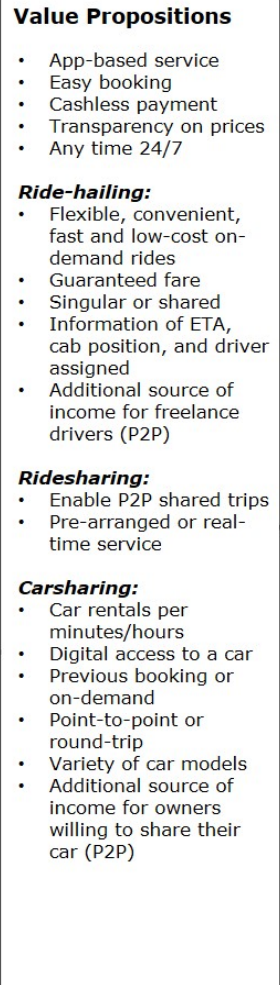 & $\begin{array}{l}\text { Channels } \\
\text {. User-friendly app } \\
\text { : Multimodal apps } \\
: \text { Mebsite } \\
\text {. Curketing } \\
\text { Ride-hailing: } \\
. \quad \text { Booking hotline } \\
\text { Ridesharing: } \\
: \text { Park-and-rides } \\
\text {. Transfer hubs } \\
\text { Carmpanies } \\
\text { Carsharing: } \\
\text {. Parking spots } \\
\text { Companies }\end{array}$ & 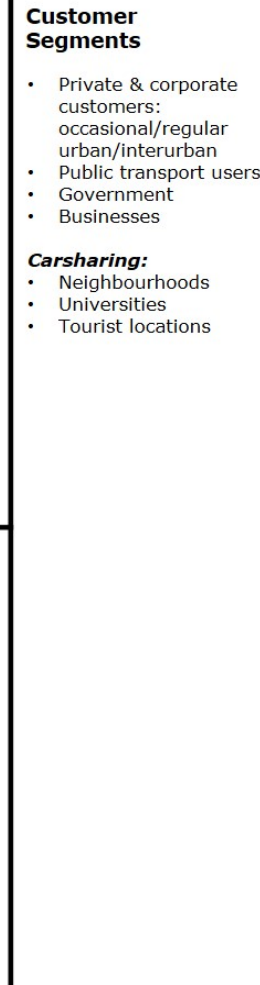 \\
\hline \multicolumn{4}{|c|}{ 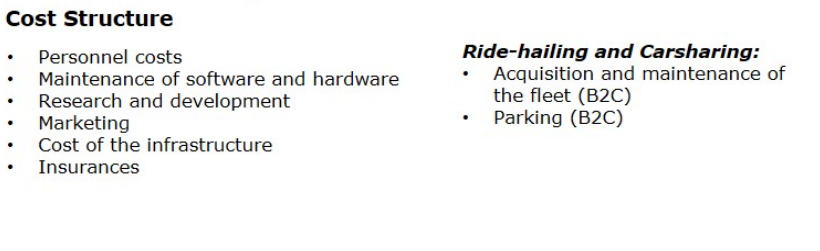 } & \multicolumn{2}{|l|}{$\begin{array}{l}\text { Revenue Streams } \\
\text {. Pay per use } \\
\text { - Commission per tran } \\
\text { Ride-hailing: } \\
\text {. Rate per km and/or } \\
\text { per min, flat rates } \\
\text {. Surge pricing } \\
\text { Extra charges for } \\
\text { additional services }\end{array}$} & $\begin{array}{l}\text { Carsharing: } \\
\text { - } \text { Registration fee, } \\
\text { monthly fee } \\
\text { - Day, hour or min. fee } \\
\text { - } \text { Rate per km } \\
\text { - Additional fees for: } \\
\text { special destinations, } \\
\text { premium car models, } \\
\text { extended reservations } \\
\text { - Sponsorship and } \\
\text { advertising }\end{array}$ \\
\hline
\end{tabular}

Figure 2. Summary of the key features of car-related shared mobility services per building block

\subsection{Customer Segments}

Car-related shared mobility services are oriented toward private customers, business clients and public authorities (Hunke, Schüritz \& Kuehl, 2017). The majority of them require users to be holders of a smartphone and a credit card, debit card, or a digital payment account, which together guarantee the reservations and cashless payments.

Some ridesharing and shared ride-hailing services target specific Customer Segments, such as commuters (Waze, 2018; Via, 2018) or long-distance travellers (Mazzell \& Sundararajan, 2016). On the other hand, singular ride-hailing services mainly target leisure, city night uses, and other short trips barely covered by the public transport or covered but with low comfort, such as trips to the airport (Lyft, 2018).

On the other hand, Cohen and Kietzmann (2014) stated that carsharing addresses individuals who aim to shift from ownership to a shared vehicle (B2C model) or to sharing the vehicles they own when not in use (P2P model). 
Shaheen and Cohen (2013) highlighted the potential of the neighbourhood, business and university customer segments, for being predominant market segments as well as the most profitable markets. Moreover, the authors also studied the carsharing addressed to government and institutions, public transit, vacation resorts and tourist locations. Lesteven and Leurent (2016) also proposed a type of carsharing for tourists, and Rotaris and Danielis (2017) analysed as well the university-sponsored carsharing targeting students and employees, the carsharing provided by public transport operators targeting public transport users, and the carsharing services owned by municipalities.

\subsection{Value Propositions}

Although each mobility service has its particular value proposition, they all have two main features in common: they are app-based and they can contribute to improve mobility, mainly in urban areas, by reducing car ownership. The greatest difference between these new transportation services and the traditional ones is that they use the latest technology, which enables users to book, ride, drive and pay in a flexible, easy and convenient way. Furthermore, Watanabe et al. (2017) pointed out that Uber (ride-hailing service) enables a faster and cheaper search for transport, and a better utilisation of assets, benefits that are also offered by the other car-related shared mobility services.

Ride-hailing services are growing as an alternative to taxis, as they offer flexible and low cost on-demand rides easily while providing a better user experience (Bonazzi \& Pigneur, 2015; Janasz \& Schneidewind, 2017; Gao \& Zhang, 2016; Watanabe, Naveed \& Neittaanmäki, 2016). However, Uber and Cabify could be more expensive when the user requests a luxury car, or when there is more demand than supply. Moreover, Cabify also gives the option to request child seats and it offers premium facilities such as $\mathrm{WiFi}$, a bottle of water and the possibility of choosing the music and temperature during the trip. According to our interviewees, their speed and convenience is what convinced them to use these services instead of using the public transport, and because of their low and guaranteed fare they chose them instead of the taxi. According to Janasz and Schneidewind (2017), ride-bailing services help solve the first- and last-mile problems. Watanabe et al. (2016) added that they also provide real-time information on the Estimated Time of Arrival (ETA) and cab position, cashless payment and time savings in reaching a location. Moreover, some ride-hailing services also provide the user with information on the assigned driver (picture, name, rates, etc.), and they offer centralised invoicing to businesses. Watanabe et al. $(2016,2017)$ also noted that ride-hailing gives transparent overview of the quality and prices. Ride-hailing is also found in the shared version, such as the operating services UberPOOL and Via.

Concerning ridesharing services, they facilitate to arrange shared trips in advance, in order that passengers can share the costs of their occasional or recurring travels between the driver and the riders, without the driver charging more money than is needed to cover the costs of fuel and vehicle depreciation. To make ridesharing easier and more flexible, this service is evolving towards real-time ridesharing (Raney, 2010; Chan \& Shaheen, 2012; Janasz \& Schneidewind, 2017). These authors highlighted the directly related benefits from the use of ridesharing, which are reductions in traffic and greenhouse gas emissions.

On the other hand, carsharing offers easy access (no paperwork required and vehicles are usually nearby) to car rentals by the minute or by the hour, usually with digital access (via a subscription card or the app). It is available at any time of the day, on-demand or with a previous booking, and without the need to return the vehicle to the pick-up location (one-way type) (Cohen \& Kietzmann, 2014; Hoffmann, Hinkeldein, Graff \& Kramer, 2014; Wu, 2016; Remane et al., 2016; Janasz \& Schneidewind, 2017). Interviewees without access to a car found carsharing very useful for day/weekend trips, to reach remote areas such as industrial parks or university campuses, and to return home after shopping. Hoffmann et al. (2014) proposed a service with a variety of car models to cover all user needs, recommended an electric fleet to move within the city centres, suggested that locations and charging stations be easily reachable and near public transport, and they mentioned users' desire for reserved parking spaces and the ability to return cars anywhere in the country. On the other hand, Cohen and Kietzmann (2014) mentioned that P2P carsharing allows car owners with underused vehicles to rent them per day in exchange for an additional source of income. 


\subsection{Channels}

App-based mobility services mainly reach their customers through their own services' applications, or through multimodal applications provided by Mobility as a Service (MaaS) platforms that include them. The majority of the user complaints of the services analysed posted on App Store and Google Play were related to app problems or bad customer service experiences. Therefore, if the application, which is the main channel, is not user-friendly or fails, not only the delivery of the Value Proposition fails, but also there is a high risk that users stop using the service. Another common and key channel for all these services is their website, since customers usually look up information here about the services and even sign up as users. In addition to well designed and user-friendly mobile apps and landing pages, communication and advertisement of these services also use email and social media marketing, online campaigns, content marketing and multichannel Business-to-Business marketing for the corporate segment (Janasz \& Schneidewind, 2017). Besides, Hoffmann et al. (2014) highlighted the importance of having a hotline to book the service in the case of ride-hailing services.

Other channels for ridesharing services are meeting places such as park and ride facilities and transfer hubs (Raney, 2010; Chan \& Shaheen, 2012; Cohen \& Kietzmann, 2014). What is more, some companies encourage their employees to commute by sharing trips with other employees (Janasz \& Schneidewind, 2017). Other essential channels that allow users to access carsharing services are parking areas, and for e-carsharing, charging stations (Shaheen et al., 2012; Hoffmann et al., 2014; Herrador, Carvalho \& Feito, 2015; Reiner \& Haas, 2015; Remane et al., 2016; Janasz \& Schneidewind, 2017).

\subsection{Customer Relationship}

Both the applications and websites of the mobility services that have been explored provide a self-service interface for customers to help themselves, although all of them offer a customer support service. However, users also need personal assistance when signing up for a carsharing service or as drivers for a ride-hailing service, since documentation needs to be checked and problems need to be resolved, such as when the requested ride-hailing or ridesharing service does not arrive, the door of rented car does not open, or the cost of the service is not correct. An important number of the reviews posted on App Store and Google Play are complaints to customer service, for being slow, not helpful or difficult to reach. Apart from that, a reputation system based on ratings or social media is widely used among these services, since it is important to enhance user confidence and assure the trust and safety of users (Shaheen et al., 2012; Wu, 2016). Furthermore, in order to retain customers, some services also offer loyalty programs. Bonazzi and Pigneur (2015) suggested social gatherings for riders and drivers and the gamification of the application. Regarding ride-hailing services that employ their drivers, these drivers also provide human interaction with the users.

\subsection{Revenue Streams}

Emerging mobility services generally charge their customers per use; however, many B2C carsharing services, such as Zipcar and Respiro, use a combination of a subscription fee and a usage fee, adapting the fee per use to the subscription chosen. Perboli, Ferrero., Musso and Vesco (2018) emphasised the importance and also the complexity of creating customised tariff plans for carsharing services.

Ride-hailing services only use the pay-per-use method, charging for each ride, but allowing for different combinations. Some apply a rate per kilometre and/or per minute, and others offer flat rates (Janasz \& Schneidewind, 2017; Pakusch, Bossauer, Shakoor \& Stevens, 2016). Moreover, during periods of high demand, Uber uses dynamic pricing to match the supply with the demand and Cabify applies an extra charge. Other extra charges are applied when requesting a service with a premium vehicle or with child seats, among other options. In P2P services, the platform charges a commission per trip, which in the case of Uber is $20 \%$ (Cohen \& Kietzmann, 2014; Gao \& Zhang, 2016; Wu, 2016).

Ridesharing services such as BlaBlaCar and Waze Carpool charge a service fee to cover the operating expenses of the platform. For instance, BlaBlaCar's commission is around 17\% of the cost of the trip (BlaBlaCar, 2016). Other 
operators such as TwoGo by SAP are subscription-based or they apply a freemium model (Janasz \& Schneidewind, 2017).

Regarding carsharing services, Remane et al. (2016) specified that their revenue model is based on a price structure that is either determined by the duration of the rental or a combination of the duration and the distance travelled. It also relies on continuous revenues and transaction-based revenues. The continuous revenues identified by Cohen \& Kietzmann (2014) and Remane et al. (2016) were membership and service fees from users, government subsidies and grants, and sponsorship and advertising. Münzel et al. (2017) distinguished the fee structure used by the operators, depending on the type of carsharing provided. Through their analysis, the authors found: most of the carsharing operators in Germany charged a registration fee, except in the case of the P2P model; cooperatives and $B 2 C$ round-trip services usually also charged a monthly fee; and, regarding the rate per use, operators of B2C round-trip services and cooperatives charged per hour or per day whilst operators of B2C one-way charged a by-the-minute fee. Interesting is the pricing model of Wible, which charges a by-the-minute fee within the first hour, per hour from the second hour onwards or a daily rate, thus combining the one-way and round-trip uses as well as the traditional car rental. Besides, Zipcar and Respiro adapt their rates depending on their different monthly subscription plans. The cheapest plan offers the most expensive rates per rental and the most expensive plan offers the cheapest rates. Additional fees could be applied depending on the car model chosen, the destination of the trip (e.g., starting or ending a rental at an airport) or for extending a reservation, which is how DriveNow works. On the other hand, P2P carsharing platforms ask for neither registration fees nor monthly fees (Wu, 2016; Münzel et al., 2017), but instead usually charge per day, as in the case of Amovens and Drivy. In this category, the prices are not regulated and thus allow car owners the freedom to set the prices for their vehicles. The carsharing platform functions as an agent that collects payment for each rental and keeps a commission for each transaction, which could be up to $25 \%$, as in the case of Turo (Wu, 2016).

\subsection{Key Resources}

Vehicles and software (user application and technological platform) are the main and common key resources of any car-related mobility service, followed by the charging infrastructure if the vehicle fleet is electric. Furthermore, resources such as smartphones and digital payment (Watanabe et al., 2016) as well as data, capital and specialists (Hunke et al., 2017) are also required for operating these services. Other key resources vary according to the different service categories.

For Ride-hailing services, in addition to the technological platform required for the characteristics of this type of service and the application for ordering rides, the following assets are equally important for being able to offer the corresponding value proposition: skilled drivers (on some occasions they are also required to hold a taxi or a VTC license, depending on the service provider and the place where the service is offered); the driver application (needed to receive user requests); vehicles adapted to the features of each service (basic, premium, sustainable, etc.); algorithms that provide routing, match different users going in the same direction and who are willing to share the ride (in the case of shared ride-hailing); algorithms that determine surge pricing, depending on the demand and supply of the moment (in the case of Uber); insurance for the service provided; and investors, who are willing to acquire a fleet of vehicles and VTC licenses, or invest money in the corresponding service provider.

Concerning ridesharing services, Raney (2010) demonstrated the importance of GPS smartphone technology and text messaging to enable real-time ridesharing and social networks to improve the user's experience. In addition, Janasz and Schneidewind (2017) added the use of automated ride matching software applications.

Besides, carsharing services require some additional key resources: digital access technology, which enables users to open the rented car by means of their smartphones; on-street and off-street parking spaces; insurance; and investment (Hampshire \& Gaites, 2011; Shaheen et al., 2012; Janasz \& Schneidewind, 2017). Furthermore, Shaheen et al. (2012) added the importance of integrating in-vehicle technology, such as control and security mechanisms, and in-vehicle data recording and transmission devices. 


\subsection{Key Activities}

All the services explored require a technological platform as a key resource. All of them must optimise and manage their online platforms, as well as promote them in order to continue acquiring customers and establishing new partnerships. Furthermore, strong customer support in case of doubts or emergency is also key to ensure the proper use of the service and to maintain and increase the user base. In this regard, Ferrero, Perboli, Rosano and Vesco (2018) highlighted the importance of an optimised fleet management and infrastructure for carsharing services, understanding fleet management activities to not only ensure that cars are in the proper condition (clean and charged/tank filled), but also the planning of the fleet size, relocation strategies, pricing and parking policies. These activities must also be conducted in ride-bailing services. However, the different service categories have distinctive features, meaning that key activities can differ depending on the corresponding service.

The key activity of ride-bailing services is to operate a fleet of vehicles in order to offer on-demand rides and, in the case of shared ride-hailing, on-demand shared rides. To make this happen, the most important actions required are varied: development and optimisation of the online platform that enables the service and, among other functions, connects drivers with passengers; development and optimisation of both user and driver applications; development and optimisation of the algorithms for routing, matching and surge pricing (if applied); obtaining and providing real-time information on the ETA and vehicle position in relation to the customer; management of the fleet; management of the reservations, cancellations, payments and contracts; marketing, in order to acquire drivers and passengers; and community management, in order to retain them. From the experience of Uber in China, Gao and Zhang (2016) highlighted key activities such as recruiting skilled drivers and providing excellent customer services to riders and drivers while building good relationships with partners. They also highlighted the importance of making it easy and convenient for drivers and riders to locate each other, and also eliminating potential risks by insuring passengers. Watanabe et al. (2016) also noted that big data analysis is an essential element; and Willing, Brandt and Neumann (2017) explained the value of customer data analytics in optimizing a service area or in tailoring any service offer. On the other hand, P2P ride-hailing services offer flexible jobs for drivers who may or may not have their own car, depending on the service provider. Some of them also offer financial aid for buying a vehicle and discounts on fuel and insurance. In this way, a key activity for P2P ride-hailing is to provide its drivers "with a bighly efficient operation without additional investment and license fees" (Watanabe et al., 2016: page 166).

The function of a ridesharing service is to connect drivers and riders going to the same destination. Since on many occasions the users do not know each other, building trust was highlighted as important by Mazzell and Sundararajan (2016). Moreover, ridesharing services are also responsible for managing the bookings and cancellations, charging the users, paying the drivers and managing the rideshare community in order to attract users and spread trust.

Carsharing services provide short-term vehicle rentals, either on-demand or by reservation. As mentioned earlier, the key activities of carsharing include, among others, the development and optimisation of the booking system's technological platform, real-time information on the availability of vehicles, and the development and optimisation of the website and user application. However, that is not all. Carsharing providers must also: manage their vehicle fleets and keep them clean, fuelled or charged, and repair and relocate them when necessary; manage the reservations, cancellations, payments and contracts; and conduct marketing campaigns. In the case of P2P carsharing, they must provide the tools (on the online platform) that allow car owners to quickly and easily post and update the information about and availability of their vehicles. Moreover, they need to attract users and car owners (P2P model) to manage the community of users and analyse the data on the operations in order to improve the service.

\subsection{Key Partnerships}

Local governments should be involved as stakeholders in defining the operation of shared mobility services in the cities (Firnkorn \& Müller, 2012; Cohen \& Kietzmann, 2014; Herrador et al., 2015; Sochor, Strömberg \& Karlsson, 2015; Watanabe et al., 2017; Janasz \& Schneidewind, 2017), since these strategic relationships are both key to providers willing to improve and expand their services, and to cities, willing to benefit from them to solve urban mobility issues. Concretely, Firnkorn and Müller (2012) suggested the development of an integrated policy framework for all cities modes of transportation, regulating three main issues for implementing these service on a 
large scale: land use as parking for carsharing services; public charging stations to charge electric fleets; and the integration with the public transport system. Besides, Janasz and Schneidewind (2017) added the necessity of having platform providers and operators for Information and Communication Technology (ICT), public transport operators, payment operators, and providers of both geo-localisation and location-based services. Additionally, Gao and Zhang (2016) also included investors, insurance companies and third-party partners, such as partners for recruiting drivers. Other partnerships established by these services include car manufacturers or car rental companies (vehicle providers), fuel or charging distributors and promotion partners. E.g. Chan and Shaheen (2012) and Herrador et al. (2015) noted that the use of ridesharing was promoted by the partnership between NuRide, public agencies and others businesses, who together sponsored incentives.

In the case of ride-bailing, which requires drivers and vehicles, either drivers provide their own cars or they are supplied by rental car companies or automakers. However, it is also possible that investors or collaborators provide the service with both, skilled/licensed drivers and a fleet of cars.

Münzel et al. (2017) related the type of carsharing provided to the type of partners among German carsharing operators: public transit, city-related partners (municipalities, local utilities and building associations) and car-related partners (car dealers, leasing or rental companies). Moreover, the authors studied the backgrounds of owners, ranging from car manufacturers, car rental companies and car dealers to rail operators and start-ups. Furthermore, B2C carsharing providers also need parking spaces for their cars, and for that reason they need to have partnerships with either private parking operators or local governments, whichever entity is the corresponding provider of regulated on-street parking. Moreover, one-way carsharing services such as car2go and DriveNow can be found in some airport parking lots. car2go also has a partnership with Lufthansa, who offers at a discount the car2go service in advance as an airport shuttle. Lesteven and Leurent (2016) designed a business model targeting tourists, which required the partnership of different players in this sector, such as hotels, amusement parks and tour agencies. In the P2P type, individual car owners are the suppliers of the vehicles, so they are the key partnership in this model.

\subsection{Cost Structure}

All three categories of the explored mobility services have similar costs, all of them being fixed costs: expenses related to the workforce, software and hardware, research and development activities, infrastructure, vehicles and the associated insurance (if owned by the service) (Lesteven \& Leurent, 2016; Hunke et al., 2017), and marketing. Additionally, B2C carsharing and ride-hailing expenses entail parking, and maintenance of the fleet as a variable cost, specifically in regard to fuelling or charging, cleaning and repairs.

\section{Discussion}

In the majority of building blocks, we found more similarities than differences among the analysed services. After comparing the different business models, we detected that these services are complementary rather than interchangeable, since they all cover different needs.

Accordingly, from the literature and the interviews analysis, we identified that car-related shared mobility services can be classified depending on the type of request (a ride or a car), the type of use (occasional or regular), and the trip distance (urban or interurban). Table 2 uses this classification to categorise the best service for each use case or customer need. For urban uses, the most suitable services are ride-hailing or one-way carsharing (which allows users to return the vehicles near their destinations at specific points (station-based) or directly on the streets (free-floating or flexible)), since both types offer on-demand and easy access to a ride or a car. Considering their revenue streams, they are suitable for a first and last mile trip, but not for an interurban travel. Instead, the round-trip model is a more suitable choice for interurban travels. Moreover, the P2P model might cover better occasional requests, whereas the B2C roundtrip model is better for regular users, since their operators usually offer subscription plans. On the other hand, for commuting or long distance trips, either occasional or regular, the most used service is ridesharing, since it is the most cost-effective option for the users.

By analysing each building block of the BMC, we also noticed that the targeted Customer Segments are complementary, since each type of service offers a different Value Proposition to cover the different user needs. This way, commuters may use a shared ride-bailing or a ridesharing service to commute, but also a singular ride-bailing 
service for leisure trips and a carsharing service for a day trip. Therefore, if services could be provided in a combined and integrated way, the value created for the targeted Customer Segments would be higher, being the most appreciated the possibility of accessing any service through the same access point: one registration, one app, one customer service. Furthermore, the analysis of the Value Proposition proves that ride-hailing, ridesharing and carsharing have similar characteristics in that they are app-based and offer easy booking and access to the service (convenience), as well as cashless payment (convenience), and firm price quotes (price). The main reason to use these services according to our surveyed users was the convenience (49\%), the price (23\%), and to test it (14\%).

\begin{tabular}{|c|c|c|c|c|c|c|}
\hline \multirow{2}{*}{$\begin{array}{l}\text { Type of } \\
\text { request }\end{array}$} & \multicolumn{2}{|c|}{ Type of use } & \multicolumn{2}{|c|}{ Trip distance } & \multirow{2}{*}{ Proposed service } & \multirow{2}{*}{ Examples } \\
\hline & Occasional & Regular & Urban & Interurban & & \\
\hline \multirow{3}{*}{ Ride } & $\mathrm{x}$ & & $\mathrm{x}$ & & $\begin{array}{c}\text { Singular } \\
\text { ride-bailing }\end{array}$ & Uber, Cabify \\
\hline & & $\mathrm{x}$ & $\mathrm{x}$ & & $\begin{array}{c}\text { Shared } \\
\text { ride-bailing }\end{array}$ & Via, Clever-Shuttle \\
\hline & $\mathrm{x}$ & $\mathrm{x}$ & & $\mathrm{x}$ & Ridesharing & $\begin{array}{l}\text { BlaBlaCar, } \\
\text { Amovens }\end{array}$ \\
\hline \multirow{3}{*}{ Car } & $\mathrm{x}$ & $\mathrm{x}$ & $\mathrm{x}$ & & B2C one-way carsharing & car2go, DriveNow, \\
\hline & & $\mathrm{x}$ & & $\mathrm{x}$ & $\begin{array}{l}\text { B2C round-trip } \\
\text { carsharing }\end{array}$ & Zipcar, Respiro \\
\hline & $\mathrm{x}$ & & & $\mathrm{x}$ & P2P round-trip carsharing & SocialCar, Drivy \\
\hline
\end{tabular}

Table 2. Classification of car-related shared mobility services according to customer needs

The majority of the characteristics in the Channels and Customer Relationships blocks are common to the three studied types of services: all need a user-friendly app, a website, and marketing actions to deliver the Value Proposition. In addition, they all want to establish a comfortable and convincing relationship with the customer, doing so in ways that range from requiring only a single registration up to offering a reputation system for improved customer service. This way, providers offering more than one service together could cut costs optimising these actions, since they could be merged. Regarding the Revenue Streams, these services are accessible through pay per use, but other revenue models could be also applied. For instance, shared mobility services could be sponsored; they could generate business with the data; or new car-related services could be offered, such as parcel delivery. Common Key Resources are vehicles and mobile applications, the technological platform, digital payment and insurances. However, ride-hailing also requires skilled and licensed drivers, as well as routing and matching algorithms, while carsharing requires parking spots, in addition to, desirably, digital access and in-vehicle technology. Common Key Activities are the development and optimisation of the platform and the corresponding apps and algorithms, as well as the management of reservations, cancellations, payments and contracts. The differences are related to the particular service features, with ride-hailing and carsharing needing to operate and manage a fleet, keep it clean and properly serviced, and to locate drivers, riders and vehicles in real time. According to Kahlen, Ketter, Lee and Gupta (2017), the optimal prepositioning and relocation of vehicles is the key to optimise the fleet size and maximise the revenues of ride-hailing and one-way carsharing services. Moreover, ride-hailing recruits' drivers whereas P2P carsharing recruits' cars to rent. Concerning Key Partnerships, the only differences are that P2P ride-bailing creates partners with freelance drivers, P2P carsharing creates partners with car owners and B2C carsharing creates partners with parking providers. Common Key Partnerships are: local governments and public transit, ICT platform providers and operators, payment operators, investors and promotion partners, and providers of vehicles, fuel or energy, insurances, and geo-localisation and location-based services. Finally, the Cost Structure is also very similar, having in common personnel costs, software and hardware maintenance, research and development activities, infrastructure and marketing; while they differ in that they have acquisition and maintenance costs of their fleet (B2C ride-hailing and B2C carsharing), and parking costs (B2C carsharing). Therefore, the Cost Structure, as well as the Key Partnerships, Key Resources and Key Activities could be also optimised if companies provide these services in an aggregated form. 
In the market, we find some operators offering two mobility services from the same application: Uber and Lyft combine the offers of singular and shared ride-hailing; Amovens provides a combined offer of ridesharing and P2P carsharing; and Cabify of ride-hailing and B2C carsharing, this last option enabled through a partnership with the car rental Bipi. These services share the app, the technological platform, Channels, Customer Relationships and Key Partnerships, but they could be further optimised if they would also share the Customer Segments, the vehicles and the fleet management. To make progress on the basis of providing an integrated service, we only found ReachNow in United States, which offered, until July 2019, carsharing and ride-hailing using the same vehicle fleet: users could rent the cars through the carsharing offer and use them to organise ride-hailing trips as drivers.

From a business point of view, the main advantages for a mobility provider in offering several services in an integrated way would be: 1 ) higher utilisation of the vehicles, since it targets different uses. This integration would enable providers to size and optimise the fleet dedicated to one or another service depending on the predicted demand. For instance, carsharing might have higher use on weekends or on public holidays, but ridesharing and shared ride-hailing during peak hours any day of the week, and singular or shared ride-hailing at nights or to go back and forth from big events; 2) optimisation of the technological platform and related development activities, as well as fleet management and marketing activities; 3) the increase of customer loyalty, since they would no longer need more than one app to access different services. On the other hand, relevant drawbacks that would prevent operators offering their services in an aggregated way would be: 1) the rise of the service management complexity, due to the real-time dimensioning and relocation of the fleet activities, and the provision of chauffeurs when required; 2) the increase of the cost structure if drivers are hired for providing ride-hailing services, although this cost would disappear with autonomous vehicles; and 3) regulatory issues, which differ between countries and even between regions and cities in the same country, and which could complicate the proposition and implementation of the service.

Another solution to help improves the profitability of mobility providers would be to outsource some key activities to third parties, who could offer the same service to other providers, reducing the cost of these activities. Alternatively, agreements between providers could be established to enable activities to be shared among their services. In this sense, the most relevant activities to outsource, or to be provided or shared with other providers, would be the customer service, and those related to technology (development, management and optimisation of the platform and applications) and operations (maintenance and fuelling/charging of vehicles). Going further in a conceptual partnership between mobility providers, some key resources could also be provided to, or received from, these partners, who in some cases might otherwise be competition. For instance, unused and non-reserved vehicles and parking spots. Focusing on ride-bailing service, and taking into account that drivers are the highest cost ridebailing service providers sustain, it might be helpful that these providers could share the same drivers, i.e. the drivers could work at the same time for more than one service. Some drivers are currently working for more than one operator (e.g. Lyft and Uber) in several cities. However, in a number of countries this might not be directly allowed, but might be enabled through outsourcing the driving services to a third company. The main risk identified in these cases, which involve a certain degree of collaboration with the competition (direct or indirect, i.e. same or different type of service offered), is the loss of the differentiation and uniqueness, leading to confusion.

\section{Conclusions}

In this paper, we explored and analysed by means of the Business Model Canvas the information available from the literature focused on business models of app-based car-related shared mobility services, from current operating services, and from the interviews. This analysis enabled us to distinguish the common features and differences of the different services, and understand that they are not interchangeable but complementary from users' perspective. Therefore, we found enough similarities to suggest that aggregated offer providers could not only share some key and costly resources and activities, but also the Channels, Customer Relationships and Key Partnerships. The main implications that this new business model would have for mobility providers is described in terms of advantages and disadvantages. Finally, the possibility to share key activities and key resources directly between mobility providers or through third party companies is discussed. 
The business models identified, based on a better use of resources, align with the forthcoming future of transportation, since autonomous cars are predicted to make carsharing services identical to private ride-bailing, which is also expected to happen with the services of shared ride-hailing and ridesharing.

Further research is needed to study the implications for practice in implementing this type of business model (involving the economic and technic feasibility), as well as implications for policy makers.

\section{Declaration of Conflicting Interests}

The authors declared no potential conflicts of interest with respect to the research, authorship, and/or publication of this article.

\section{Funding}

This work was supported by SEAT, S.A., and Secretariat of Universities and Research of Generalitat de Catalunya [grant number 2016 DI 023].

\section{References}

Alonso-Mora, J., Samaranayake, S., Wallar, A., Frazzoli, E., \& Rus, D. (2017). On-demand high-capacity ride-sharing via dynamic trip-vehicle assignment. Proceedings of the National Academy of Sciences, 114(3), 462-467.

https://doi.org/10.1073/pnas.1611675114

Amovens Soluciones (2017). Amovens. Available at: https://amovens.com (Accessed: July 2017).

Apple Inc. (2018). App Store. Available at: https://www.apple.com/ios/app-store (Accessed: November 2018)

Bälan, C. (2016). Ride-sharing and car-sharing in Romania: What choices do potential users have? Presented at the International Conference of the Institute for Business Administration in Bucharest. Bucharest.

BlaBlaCar (2016). BlaBlaCar: Gastos de gestión. Available at: https://www.blablacar.es/blablalife/lp/gastos-de-gestion (Accessed: January 2018)

BlaBlaCar (2018). Compartir coche para llegar directamente a donde quieras ir. Available at: https://www.blablacar.es (Accessed: January 2018)

Bonazzi, R., \& Pigneur, Y. (2015). The Hitchbiker's Guide to the Galaxy of Dynamic Ridesharing (1207-1216). https://doi.org/10.1109/HICSS.2015.146

car2go (2017). Car2go. Available at: https://www.car2go.com (Accessed: July 2017)

Chan, N.D., \& Shaheen, S.A. (2012). Ridesharing in North America: Past, Present, and Future. Transport Reviews, 32(1), 93-112. https://doi.org/10.1080/01441647.2011.621557

CleverShuttle (2018). CleverShuttle | RidePooling-Fahrdienst - Pay Less. Move Green. Available at: https://www.clevershuttle.de (Accessed: August 2018)

Cohen, B., \& Kietzmann, J. (2014). Ride on! Mobility business models for the sharing economy. Organization \& Environment, 27(3), 279-296. https://doi.org/10.1177/1086026614546199

Didi Chuxing (2018). Didi Chuxing. Available at: http://www.didichuxing.com/en (Accessed: May 2018)

DriveNow (2017). Carsharing by BMW i, MINI and Sixt. Available at: https://de.drive-now.com/en (Accessed: July 2017)

Drivy (2017). Drivy. Available at: https://www.drivy.es (Accessed: July 2017)

Ferrero, F., Perboli, G., Rosano, M., \& Vesco, A. (2018). Car-sharing services: An annotated review. Sustainable Cities and Society, 37, 501-508. https://doi.org/10.1016/j.scs.2017.09.020

Firnkorn, J., \& Müller, M. (2012). Selling Mobility instead of Cars: New Business Strategies of Automakers and the Impact on Private Vehicle Holding: Selling Mobility instead of Cars. Business Strategy and the Environment, 21(4), 264-280. https://doi.org/10.1002/bse.738 
Gao, S., \& Zhang, X. (2016). Understanding Business Models in the Sharing Economy in China: A Case Study. Social Media: The Good, the Bad, and the Ugly, 9844, 661-672. https://doi.org/10.1007/978-3-319-45234-0_59

Gett (2017). Gett. Available at: http://gett.com/ (Accessed: July 2017)

Goldman, H. (2017). After London Bans Uber, New York Weighs Limits to Help Cabbies. Available at: https://www.bloomberg.com/news/articles/2017-09-25/after-london-bans-uber-new-york-weighs-limits-to-help-cabbies (Accessed: November 2018)

Google (2018). Google Play. Available at: https://play.google.com/store?hl=es (Accessed: November 2018)

Hampshire, R., \& Gaites, C. (2011). Peer-to-Peer Carsharing: Market Analysis and Potential Growth. Transportation Research Record: Journal of the Transportation Research Board, 2217, 119-126. https://doi.org/10.3141/2217-15

Herrador, M., Carvalho, A., \& Feito, F. (2015). An Incentive-Based Solution of Sustainable Mobility for Economic Growth and CO2 Emissions Reduction. Sustainability, 7(5), 6119-6148. https://doi.org/10.3390/su7056119

Hoffmann, C., Hinkeldein, D., Graff, A., \& Kramer, S. (2014). What Do Potential Users Think About Electric Mobility? In Hülsmann, M., \& Fornahl, D. (Eds.), Evolutionary Paths Towards the Mobility Patterns of the Future (85-99). Available at: http://link.springer.com/10.1007/978-3-642-37558-3 6

Hunke, F., Schüritz, R., \& Kuehl, N. (2017). Towards a Unified Approach to Identify Business Model Patterns: A Case of E-Mobility Services. In Za, S., Drăgoicea, M., \& Cavallari, M. (Eds.), Exploring Services Science (vol. 279, 182-196). Available at: http://link.springer.com/10.1007/978-3-319-56925-3 15

Janasz, T., \& Schneidewind, U. (2017). The Future of Automobility. In Oswald, G., \& Kleinemeier, M. (Eds.), Shaping the Digital Enterprise (253-285). Available at: http://link.springer.com/10.1007/978-3-319-40967-2 13

Kahlen, M., Ketter, W., Lee, T., \& Gupta, A. (2017). Optimal Prepositioning and Fleet Sizing to Maximize Profits for One-way Transportation Companies. ICIS 2017 Proceedings, 3. Available at: https://aisel.aisnet.org/icis2017/TransformingSociety/Presentations/3/?utm source=aisel.aisnet.org $\% 2$ Ficis $2017 \% 2$ FTransformingSociety $\% 2 F$ Presentations $\% 2 F 3 \& u t m$ medium=PDF\&utm campaign=PDFCoverPages

Lesteven, G., \& Leurent, F. (2016). Electromobility for Tourists: Testing Business Models in the Paris Region. Transportation Research Procedia, 19, 164-175. https://doi.org/10.1016/j.trpro.2016.12.077

Lyft. (2018). Ride with Lyft. Available at: https://www.lyft.com/rider (Accessed: November 2018)

Martínez, L., Viegas, J., Crist, P., \& Martinie, M. (2015). Urban Mobility System Upgrade: How Shared Self-Driving Cars Could Change City Traffic [Corporate Partnership Board Report]. Available at: https://www.itfoecd.org/sites/default/files/docs/15cpb self-drivingcars.pdf

Maxi Mobility S.L. (2017). Cabify. Available at: https://cabify.com (Accessed: July 2017)

Mazzell, F., \& Sundararajan, A. (2016). Entering the trust age. BlaBlaCar. New York University.

Morozov, E. (2016). Silicon Valley, el nuevo centro de poder ¿será la capital de un imperio que gobernará el mundo? Vanguardia Dossier, 63, 21-26.

Münzel, K., Boon, W., Frenken, K., \& Vaskelainen, T. (2017). Carsharing business models in Germany: characteristics, success and future prospects. Information Systems and E-Business Management. https://doi.org/10.1007/s10257-017-0355-x

mytaxi. (2017). mytaxi - The Taxi App. Available at: https://us.mytaxi.com/index.html (Accessed: July 2017)

Osterwalder, A., Pigneur, Y., \& Tucci, C.L. (2005). Clarifying Business Models: Origins, Present, and Future of the Concept. Communications of the Association for Information Systems, 15. https://doi.org/10.17705/1CAIS.01601

Pakusch, C., Bossauer, P., Shakoor, M., \& Stevens, G. (2016). Using, Sharing, and Owning Smart Cars - A Future Scenario Analysis Taking General Socio-Technical Trends into Account (19-30). https://doi.org/10.5220/0005960900190030

Perboli, G., Ferrero, F., Musso, S., \& Vesco, A. (2018). Business models and tariff simulation in car-sharing services. Transportation Research Part A, 115, 32-48. https://doi.org/10.1016/j.tra.2017.09.011 
Raney, S. (2010). San Francisco to Silicon Valley, California, Instant Ridesharing with Transfer Hub. Transportation Research Record: Journal of the Transportation Research Board, 2143, 134-141. https://doi.org/10.3141/2143-17

ReachNow LLC. (2018). ReachNow - BMW Car Sharing \& Car Rental. Available at: https://reachnow.com/en (Accessed: November 2018)

Reiner, R., \& Haas, H. (2015). Stuttgart Region-From E-Mobility Pilot Projects to Showcase Region. In Leal-Filho, W., \& Kotter, R. (Eds.), E-Mobility in Europe (179-186). Available at: http://link.springer.com/10.1007/978-3-319-13194$\underline{810}$

Remane, G., Nickerson, R.C., Hanelt, A., Tesch, J.F., \& Kolbe, L.M. (2016). A Taxonomy of Carsharing Business Models. Presented at the Thirty Seventh International Conference on Information Systems. Dublin. https://doi.org/10.1007/978-3-658-18613-5_22

Respiro (2018). Alquiler de coches por horas o días - Car Sharing Respiro. Available at: https://www.respiro.es (Accessed: November 2018)

Rotaris, L., \& Danielis, R. (2017). The role for carsharing in medium to small-sized towns and in less-densely populated rural areas. Transportation Research Part A: Policy and Practice. https://doi.org/10.1016/j.tra.2017.07.006

Shaheen, S.A., \& Cohen, A.P. (2013). Carsharing and Personal Vehicle Services: Worldwide Market Developments and Emerging Trends. International Journal of Sustainable Transportation, 7(1), 5-34. https://doi.org/10.1080/15568318.2012.660103

Shaheen, S.A., Mallery, M.A., \& Kingsley, K.J. (2012). Personal vehicle sharing services in North America. Research in Transportation Business \& Management, 3, 71-81. https://doi.org/10.1016/j.rtbm.2012.04.005

Sochor, J., Strömberg, H., \& Karlsson, I.C.M. (2015). Implementing Mobility as a Service: Challenges in Integrating User, Commercial, and Societal Perspectives. Transportation Research Record: Journal of the Transportation Research Board, 2536, 1-9. https://doi.org/10.3141/2536-01

SocialCar (2017). SocialCar. Available at: https://www.socialcar.com (Accessed: January 2017)

Uber (2017). Uber - Earn Money by Driving or Get a Ride Now [Uber]. Available at: https://www.uber.com (Accessed: July 2017)

Via (2018). Smarter shared rides. Available at: https://ridewithvia.com (Accessed: May 2018)

Watanabe, C., Naveed, K., \& Neittaanmäki, P. (2016). Co-evolution of three mega-trends nurtures un-captured GDP - Uber's ride-sharing revolution. Technology in Society, 46, 164-185.

https://doi.org/10.1016/j.techsoc.2016.06.004

Watanabe, C., Naveed, K., Neittaanmäki, P., \& Fox, B. (2017). Consolidated challenge to social demand for resilient platforms - Lessons from Uber's global expansion. Technology in Society, 48, 33-53.

https://doi.org/10.1016/j.techsoc.2016.10.006

Waze (2018). Make the most of your commute. Available at: https://www.waze.com/en/carpool (Accessed: November 2018)

Wible (2018). Wible - Carsharing - zero emission en Madrid, España. Available at: http://www.wible.es (Accessed: November 2018)

Willing, C., Brandt, T., \& Neumann, D. (2017). Electronic mobility market platforms - a review of the current state and applications of business analytics. Electronic Markets, 27(3), 267-282. https://doi.org/10.1007/s12525-017-0257-2

Wu, L. (2016). Understanding Collaborative Consumption Business Model: Case of Car Sharing Systems. DEStech (403-409). Beijing: Destech Publicat Inc. https://doi.org/10.12783/dtmse/mmme2016/10146

Zhang, R., Spieser, K., Frazzoli, E., \& Pavone, M. (2015). Models, algorithms, and evaluation for autonomous mobility-on-demand systems. American Control Conference (ACC) (2573-2587). Available at: http://ieeexplore.ieee.org/abstract/document/7171122 
Zipcar (2017). Car Sharing: An Alternative to Car Rental with Zipcar. Available at: https://www.zipcar.com (Accessed: July 2017)

Journal of Industrial Engineering and Management, 2019 (www.jiem.org)

\section{(1) $(\Theta$}

Article's contents are provided on an Attribution-Non Commercial 4.0 Creative commons International License. Readers are allowed to copy, distribute and communicate article's contents, provided the author's and Journal of Industrial Engineering and Management's names are included. It must not be used for commercial purposes. To see the complete license contents, please visit https://creativecommons.org/licenses/by-nc/4.0/. 